\title{
The Pattern of Risk Factor Profile and Dutch Lipid Clinic Network Criteria of Familial Hypercholesterolemia in Egyptian Patients with Premature Coronary Heart Disease
}

\author{
Ahmed Ellaien", Ashraf Reda, Ahmed Elkersh \\ Cardiology Department, Faculty of Medicine, Menofia University, Menofia, Egypt \\ Email address: \\ ahmed.ellain@med.menofia.edu.eg (A. Ellaien), ashrafreda5555@gmail.com (A. Reda), ahmedelkersh0@gmail.com (A. Elkersh) \\ ${ }^{*}$ Corresponding author \\ To cite this article: \\ Ahmed Ellaien, Ashraf Reda, Ahmed Elkersh. The Pattern of Risk Factor Profile and Dutch Lipid Clinic Network Criteria of Familial \\ Hypercholesterolemia in Egyptian Patients with Premature Coronary Heart Disease. Cardiology and Cardiovascular Research. \\ Vol. 4, No. 4, 2020, pp. 203-209. doi: 10.11648/j.ccr.20200404.16
}

Received: October 11, 2020; Accepted: October 21, 2020; Published: October 30, 2020

\begin{abstract}
Background: Traditional risk factors (RFs), such as obesity, family history of premature coronary heart disease (CHD), hypertension, diabetes mellitus, and cigarette smoking have been shown to be significantly associated with early-onset CHD. Familial hypercholesterolemia (FH) is also a major genetic risk factor of premature CHD. Methods: This study was conducted on 100 patients with premature CHD (age $<55$ years in males and $<60$ years in females) who were admitted to hospital with acute coronary syndrome or stable coronary artery disease referred for coronary angiography, with a focus on RFs. Results: Male patients constituted $74 \%$ of the patients. In all patients, smoking (64\%), obesity (64\%), abdominal obesity (71\%), increased LDL cholesterol (67\%), hypertension (54\%), positive family history of CHD (43\%), and diabetes mellitus (34\%) were the most prevalent risk factors. There were 26 patients diagnosed as having definite/probable FH (26\%) using DLCNC score. The most common diagnosis was St-elevation myocardial infarction (STEMI) (53\%) which was more prevalent in males compared to females [(60.8\%) vs $(30.8 \%),(p<0.001)]$. Female patients had higher prevalence of hypertension [(73.1\%) vs $(47.3 \%),(p=0.023)]$, diabetes mellitus [(53.8\%) vs $(27 \%),(p=0.013)]$, Obesity $[(80.8 \%)$ vs $(58.1 \%),(\mathrm{P}=0.038)]$ and definite/probable FH $[(46.1 \%)$ vs $(18.9 \%),(p=0.024)]$ as compared to male patients. On the other hand, male patients had higher prevalence of smoking [(85.1\%) vs $(3.8 \%),(p<0.001)]$ and reduced HDL cholesterol levels [(73\%) vs $(42.3 \%)$, $(p=0.005)]$ compared to female patients. Conclusions: Traditional risk factors and FH were significantly related to premature CHD. Significant sex differences were also observed for multiple RFs.
\end{abstract}

Keywords: Risk Factors, Premature Coronary Heart Disease, Young, Familial Hypercholesterolemia

\section{Introduction}

Coronary heart disease (CHD) is the most common contributing factor of cardiovascular morbidity and mortality worldwide. [1] Incidence of premature coronary heart disease is quiet high. It is estimated that 1 to $7 \%$ of patients with atherosclerosis are young adults, depending on the age limit used to determine premature atherosclerosis. [2] The incidence of premature CHD increases in many regions of the world and starts even at earlier age, despite major advances in the prevention and treatment of atherosclerosis.

In many studies, traditional risk factors (RFs), such as family history of premature CHD, dyslipidemia, hypertension, obesity, diabetes mellitus, and cigarette smoking have been shown to be significantly associated with early CHD. [3-5] Familial hypercholesterolemia (FH) is also a major genetic risk factor of premature $\mathrm{CHD}$, due to persistent and lifelong elevation of plasma low-density lipoprotein (LDL) cholesterol levels. [6] Once diagnosed, heterozygous FH usually can be treated with cholesterol lowering therapies and hence decelerate the progression of premature atherosclerosis. However, FH is still under diagnosed because there is still deficient awareness among the general population and pediatricians about $\mathrm{FH}$, so the diagnosis is often settled late after atherosclerosis has been established. 
There are, however, few studies that focus on the prevalence of these RFs in young adults in the Egyptian population. In these younger groups of patients, preventive measures are likely to be effective and early diagnosis of the disease is of great importance, which if happens, would reduce its morbidity and mortality. [5] The primary objective of this study was describing the pattern of different risk factors including familial hypercholestrolemia among Egyptian patients with premature coronary heart disease. A secondary aim was to explore gender differences regarding different risk factors.

\section{Methods}

The study was approved by the hospital's Ethical Review Board (Menofia university hospitals, faculty of medicine, Menofia, Egypt). Detailed information was given to each patient prior to enrolment in this study, and data were included only after obtaining signed informed consent from all patients.

We studied 100 consecutive available patients (age $<60$ years in females and $<55$ years in males) admitted to Menofia University Hospitals Coronary care unit and presented with acute coronary syndrome or referred for coronary angiography with proven CHD in 2 predetermined days per week (Saturday \& Monday). The study was conducted over a period of 6 months (from November 2019 to April 2020).

Based on patient presentations, electrocardiogram (ECG) and cardiac troponins, patients were classified as having: STElevation Myocardial Infarction (STEMI), Non-ST-Elevation Myocardial Infarction (NSTEMI), Unstable Angina (UA) or Stable coronary artery disease (SCAD). Patients who were receiving any type of lipid lowering drugs in past 6 weeks before admission were excluded from the study.

Clinical data including socio-demographics, history of comorbidities, presenting symptoms, cardiovascular risk factors and laboratory data were obtained from all patients. Hypertension was defined as having a history of hypertension or systolic/diastolic blood pressure $\geq 140 / 90 \mathrm{mmHg}$. [7] Diabetes mellitus (type 1 or 2) were defined as having a history of diabetes or fasting plasma glucose $>126 \mathrm{mg} / \mathrm{dl}$. [8] Dyslipidemia was considered when total cholesterol (TC) level was exceeding ( $>200 \mathrm{mg} / \mathrm{dl}$ ), or high triglycerides (TG) $(>150 \mathrm{mg} / \mathrm{dl})$, or high low density lipoprotein cholesterol (LDL-C) $(>130 \mathrm{mg} / \mathrm{dl})$, or low high density lipoprotein (HDL-C) $(<40 \mathrm{mg} / \mathrm{dl})$. [9] Body weight and height were measured while the patients were barefoot and wearing light clothes. Body mass index (BMI) was calculated as weight $(\mathrm{kg}) /$ height squared $\left(\mathrm{m}^{2}\right)$. Patients were considered obese if they had a BMI $\geq 30 \mathrm{~kg} / \mathrm{m}^{2}$. [10] Waist circumference was measured with a non-stretchable measuring tape at the level of the umbilicus. Abdominal obesity was defined as a waisthip ratio above 0.90 for males and above 0.85 for females. [11] Blood samples were collected within 24 hours of hospital admission and were analyzed in accredited laboratories of our hospital.

Clinical FH was diagnosed using the Dutch Lipid Clinic
Network Criteria (DLCNC) score. Numerical scores were assigned as follows: (1) family history of a first-degree relative with known premature CHD or vascular disease $(<55$ years for males, $<60$ years for females) (1 point) and/or a first-degree relative with known hypercholesterolemia (1 point) or xanthomas and/or arcus cornealis (2 points) or offspring (s) with known hypercholesterolemia (2 points). (2) Personal history of premature CHD-ages as above-(2 points) or premature cerebral/peripheral vascular disease (1 point). (3) Physical examination of the patient shows xanthomas (6 points) or arcus cornealis $<45$ years ( 4 points). (4) Untreated LDL-C $>8.5 \mathrm{mmol} / \mathrm{L}$ (8 points), $6.5 \sim 8.4 \mathrm{mmol} / \mathrm{L}$ (5 points), $5.0 \sim 6.4 \mathrm{mmol} / \mathrm{L}$ (3 points), or $4.0 \sim 4.9 \mathrm{mmol} / \mathrm{L}$ (1 point). Genetic diagnosis was not available, and this missing information was counted as zero. Finally, a diagnosis of definite $\mathrm{FH}$ was considered if the total score was $>8$ points, probable if the score was $6 \sim 8$ points, possible if the score was $3 \sim 5$ points and unlikely if the score was $<3$ points. [12]

Primary outcomes of interest were the overall prevalence of different RFs in the studied patients and sex differences in RFs prevalence.

\section{Statistical Analysis}

All data analysis was performed using Statistical Program for Social Science (SPSS) version 26. [13] Qualitative data were presented as frequency and percentage. Quantitative data were presented as mean \pm standard deviation (SD). A oneway analysis of variance (ANOVA) was used when comparing between more than two means if data was normally distributed. Kruskal-Wallis test was used when the normality, homogeneity of variance, or outliers' assumptions for One-way ANOVA were not met whereas Chi-square (X2) test of significance was used in order to compare proportion between two qualitative parameters. Results with ( $p$ value $<0.05)$ were considered significant and results with $(p$ value $>0.05$ ) were considered insignificant.

\section{Results}

This study was carried out on 100 patients with premature CHD (74 males \& 26 females). Their mean age was $(49.17 \pm 6.86)$ years. Divisions of patients were made according to gender into males and females and age into 4 groups; group 1 ( $<35$ years) had a total of 2 patients ( 1 male $\& 1$ female), group 2 (36-45 years) had a total of 21 patients (18 males and 3 females), group 3 (46-55 years) had a total of 67 patients (51 males and 16 females) and group 4 (56-60 years) had a total of 10 patients (4 males and 6 females). Majority of patients were in group 3 (67\%).

Education status was higher in males, as secondary school and higher education levels were higher in males $(48.6 \%)$ and $(32.4 \%)$ compared to females $(30.8 \%)$ and $(15.4 \%)$, respectively $(p<0.001)$. The most common presentation of premature CHD among study population was STEMI (53\%) and this diagnosis was more prevalent in males compared to females $[(60.8 \%)$ vs $(30.8 \%), \quad(p<0.001)]$. Meanwhile, 
NSTEMI diagnosis was more prevalent in females compared to males $[(53.8 \%)$ vs $(20.3 \%),(p=0.008)]$. (Table 1$)$

Sixty four patients were obese $(64 \%)$. Fifty four patients had hypertension (54\%). Thirty four patients had diabetes (34\%). Smoking was documented in 64 patients (64\%). Seventy one patients had increased waist/hip ratio (71\%). Positive family history of premature CHD was present in (43\%) of the participants. There were 26 patients identified as having definite/probable FH (26\%) using DLCNC score. Mean values (mg/dl) for TC, HDL-C, LDL-C and TG were (226.48), (37.81), (159.96) and (169.01) respectively. Hypercholesterolemia was present in $(62 \%)$ of patients, Low HDL-C in $(65 \%)$ of patients, increased LDL-C in $(67 \%)$ and increased TG in (47\%) of patients. (Table 2-Table 3 )

Prevalence of hypertension, diabetes mellitus and obesity were higher in older age group $4,(80 \%),(70 \%)$ and $(80 \%)$, respectively. There was a trend for an increase in metabolic risk factors with advancing of age. On the other hand, prevalence of smoking was higher in middle age groups 2 and 3. (Table 2) Female patients had increased prevalence of hypertension [(73.1\%) vs $(47.3 \%),(p=0.023)]$, diabetes mellitus $[(53.8 \%)$ vs $(27 \%),(p=0.013)]$, Obesity [(80.8\%) vs $(58.1 \%),(p=0.038)]$ and definite/probable $\mathrm{FH}[(46.1 \%)$ vs $(18.9 \%),(p=0.024)]$ as compared to male patients. On the other hand, male patients had increased prevalence of smoking $[(85.1 \%)$ vs $(3.8 \%),(\mathrm{P}<0.001)]$ and reduced HDL-C $[(73 \%)$ vs $(42.3 \%),(p=0.005)]$ compared to female patients. However, there was no significant difference between male and female patients in presence of family history of CHD $[(40.5 \%)$ vs $(50 \%),(p=0.402)]$, increased waist/hip ratio $[(68.9 \%)$ vs $(76.9 \%), \quad(p=1.000)]$, hypercholesterolemia $[(60.8 \%)$ vs $(65.4 \%),(p=0.679)]$, increased TG $[(45.9 \%)$ vs $(50 \%), \quad(\mathrm{P}=0.722)]$ and increased LDL-C $[(66.2 \%)$ vs $(69.2 \%),(p=0.779)]$. (Table 3)

Table 1. Socio-demographics and clinical characteristics at presentation between males and females.

\begin{tabular}{llll}
\hline Variables & Total population $(\mathbf{n}=\mathbf{1 0 0})$ & Males $(\mathbf{n}=\mathbf{7 4 )}$ & Females (n=26) \\
\hline Age, years & $(49.17 \pm 6.86)$ & $(49.17 \pm 6.86)$ & $(50.81 \pm 7.94)$ \\
Married & $98(98 \%)$ & $73(98.6 \%)$ & $25(96.2 \%)$ \\
Education & & & 0.244 \\
None & $12(12 \%)$ & $1(4.1 \%)$ & 0.201 \\
Primary School & $16(16 \%)$ & $11(14.9 \%)$ & $5(19.2 \%)$ \\
Secondary School & $44(44 \%)$ & $36(48.6 \%)$ & $8(30.8 \%)$ \\
University/college & $28(28 \%)$ & $26(32.4 \%)$ & $2(15.4 \%)$ \\
Presenting diagnosis & & & $8(30.8 \%)$ \\
STEMI & $53(53 \%)$ & $45(60.8 \%)$ & $15(53.8 \%)$ \\
NSTEMI & $29(29 \%)$ & $14(20.3 \%)$ & $31(1.5 \%)$ \\
UA & $9(9 \%)$ & $6(8.1 \%)$ & 0.001 \\
SCAD & $9(9 \%)$ & $9(12.2 \%)$ & $0.00 \%)$ \\
\hline
\end{tabular}

Table 2. Prevalence of risk factors by age.

\begin{tabular}{|c|c|c|c|c|c|c|}
\hline Variables & Total population $(n=100)$ & Group $1(n=2)$ & Group $2(n=21)$ & Group $3(n=67)$ & Group $4(n=10)$ & p-value \\
\hline Males & $74(74 \%)$ & $1(50 \%)$ & $18(85.7 \%)$ & $51(76.1 \%)$ & $4(40 \%)$ & 0.041 \\
\hline Females & $26(26 \%)$ & $1(50 \%)$ & $3(14.3 \%)$ & $16(23.9 \%)$ & $6(60 \%)$ & 0.041 \\
\hline HTN & $54(54 \%)$ & $0(0 \%)$ & $4(19.1 \%)$ & $42(62.7 \%)$ & $8(80 \%)$ & 0.044 \\
\hline DM & $34(34 \%)$ & $0(0 \%)$ & $5(23.8 \%)$ & $22(32.8 \%)$ & $7(70 \%)$ & 0.036 \\
\hline Smoking & $64(64 \%)$ & $1(50 \%)$ & $16(76.2 \%)$ & $45(67.2 \%)$ & $2(20 \%)$ & 0.012 \\
\hline Obesity & $64(64 \%)$ & $0(0 \%)$ & $8(38.1 \%)$ & $48(71.6 \%)$ & $8(80 \%)$ & 0.06 \\
\hline Family history of CHD & $43(43 \%)$ & $1(50 \%)$ & $9(42.9 \%)$ & $31(46.3 \%)$ & $2(20 \%)$ & 0.477 \\
\hline
\end{tabular}

Table 3. Risk factors, anthropometric measures and serum biochemical parameters in males and females.

\begin{tabular}{|c|c|c|c|c|}
\hline & Total population $(n=100)$ & Males $(n=74)$ & Females $(n=26)$ & p-value \\
\hline \multicolumn{5}{|l|}{ Traditional cardiovascular risk factors } \\
\hline HTN & $54(54 \%)$ & $35(47.3 \%)$ & $19(73.1 \%)$ & 0.023 \\
\hline DM & $34(34 \%)$ & $20(27 \%)$ & $14(53.8 \%)$ & 0.013 \\
\hline Smoking & $64(64 \%)$ & $63(85.1 \%)$ & $1(3.8 \%)$ & $<0.001$ \\
\hline Obesity & $64(64 \%)$ & $43(58.1 \%)$ & $21(80.8 \%)$ & 0.038 \\
\hline Family history of CHD & $43(43 \%)$ & $30(40.5 \%)$ & $13(50 \%)$ & 0.402 \\
\hline \multicolumn{5}{|l|}{ DLCNC score } \\
\hline Less than 3 (unlikely) & $33(33 \%)$ & $29(39.2 \%)$ & $4(15.4 \%)$ & \multirow{4}{*}{0.024} \\
\hline 3-5 (possible) & $41(41 \%)$ & $31(41.9 \%)$ & $10(38.5 \%)$ & \\
\hline 6-8 (probable) & $21(21 \%)$ & $12(16.2 \%)$ & $9(34.6 \%)$ & \\
\hline More than 8 (Definite) & $5(5 \%)$ & $2(2.7 \%)$ & $3(11.5 \%)$ & \\
\hline \multicolumn{5}{|l|}{ Serum Biochemical parameters } \\
\hline Total Cholesterol, mg/dl (mean \pm SD) & $226.48 \pm 56.18$ & $226.01 \pm 52.94$ & $227.81 \pm 65.67$ & 0.889 \\
\hline HDL cholesterol, mg/dl (mean $\pm \mathrm{SD})$ & $37.81 \pm 8.94$ & $36.43 \pm 8.94$ & $41.73 \pm 7.85$ & 0.009 \\
\hline LDL cholesterol, mg/dl (mean \pm SD) & $159.96 \pm 54.71$ & $154.14 \pm 50.32$ & $176.54 \pm 63.82$ & 0.072 \\
\hline Triglycerides, mg/dl (mean \pm SD) & $169.01 \pm 85.35$ & $172.19 \pm 90.33$ & $159.96 \pm 70.02$ & 0.532 \\
\hline Total Cholesterol>200 mg/dl & $62(62 \%)$ & $45(60.8 \%)$ & $17(65.4 \%)$ & 0.679 \\
\hline HDL cholesterol $<40 \mathrm{mg} / \mathrm{dl}$ & $65(65 \%)$ & $54(73 \%)$ & $11(42.3 \%)$ & 0.005 \\
\hline
\end{tabular}




\begin{tabular}{|c|c|c|c|c|}
\hline & Total population $(n=100)$ & Males $(n=74)$ & Females $(n=26)$ & p-value \\
\hline LDL cholesterol $>130 \mathrm{mg} / \mathrm{dl}$ & $67(67 \%)$ & $49(66.2 \%)$ & $18(69.2 \%)$ & 0.779 \\
\hline Triglycerides $>150 \mathrm{mg} / \mathrm{dl}$ & $47(47 \%)$ & $34(45.9 \%)$ & $13(50 \%)$ & 0.722 \\
\hline $\mathrm{Hb}(\mathrm{gm} / \mathrm{dl})($ mean $\pm \mathrm{SD})$ & $14.02 \pm 2.01$ & $14.68 \pm 1.70$ & $12.13 \pm 1.59$ & $<0.001$ \\
\hline Serum creatinine $(\mathrm{mg} / \mathrm{dl})(\mathrm{mean} \pm \mathrm{SD})$ & $0.96 \pm 0.22$ & $0.98 \pm 0.21$ & $0.87 \pm 0.24$ & 0.02 \\
\hline \multicolumn{5}{|l|}{ Anthropometric measures } \\
\hline Weight $(\mathrm{Kg})($ mean \pm SD) & $93.77 \pm 13.15$ & $93.39 \pm 12.78$ & $94.85 \pm 34.36$ & 0.630 \\
\hline Height $(\mathrm{cm})($ mean \pm SD) & $171.31 \pm 8.75$ & $172.68 \pm 8.63$ & $167.42 \pm 8.04$ & 0.008 \\
\hline Waist circumference $(\mathrm{cm})($ mean $\pm \mathrm{SD})$ & $102 \pm 10.2$ & $100.8 \pm 7.1$ & $101 \pm 8.7$ & 0.679 \\
\hline Waist/ hip ratio (mean $\pm \mathrm{SD}$ ) & $0.98 \pm 0.17$ & $0.97 \pm 0.16$ & $0.99 \pm 0.16$ & 0.550 \\
\hline Obesity (BMI>30) & $64(64 \%)$ & $43(58.1 \%)$ & $21(80.8 \%)$ & 0.038 \\
\hline Abnormal waist/hip ratio & $71(71 \%)$ & $51(68.9 \%)$ & $20(76.9 \%)$ & 1.000 \\
\hline
\end{tabular}

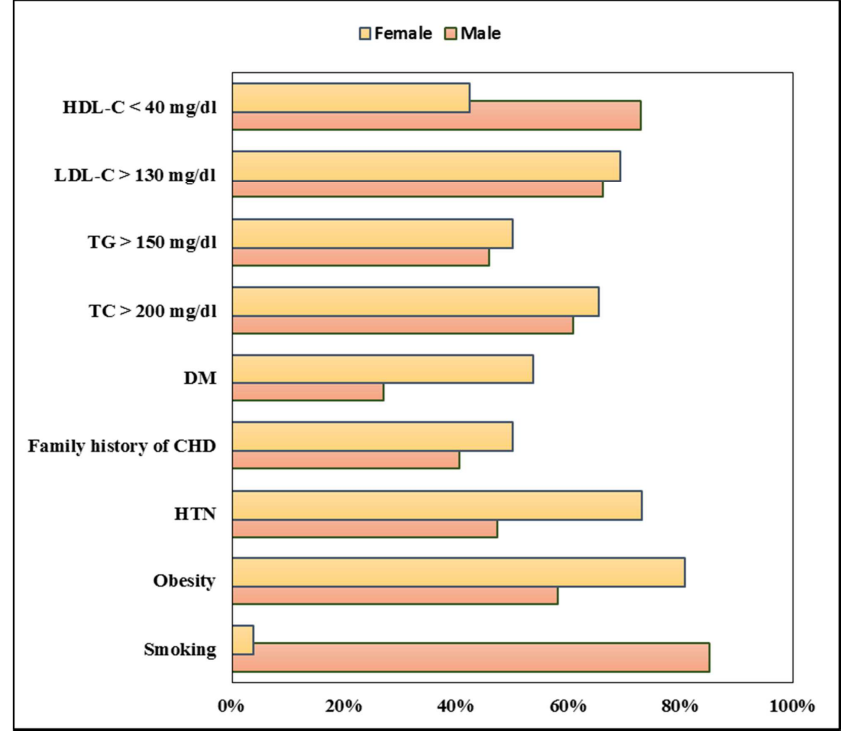

Figure 1. Gender-specific prevalence of traditional cardiovascular risk factors, $n=74$ males and 26 females.

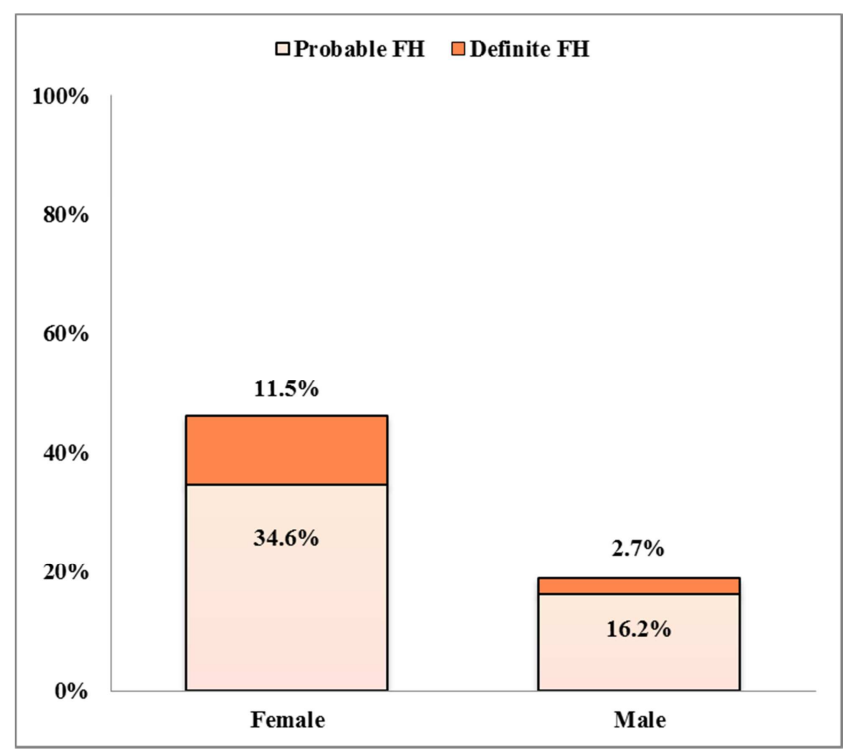

Figure 2. Prevalence of clinical familial hypercholesterolaemia among males and females with premature CHD.

\section{Discussion}

Our study was carried out on 100 patients presented with premature CHD (74 males \& 26 females) aged from 24 years to 59 years. We found that male to female ratio was $(2.8: 1)$, while other studies conducted worldwide reported significantly higher male to female ratio. Egiziano et al. conducted a study including 10619 patients with premature CHD and reported a males to female ratio of 4.5:1. [14] The lower ratio in the Egyptian population denotes that female patients with early onset CHD need to be further studied to address the different risk factors.

We noticed that in age group 2 (36-45 years) males constituted $(85.7 \%)$ of the patients compared to females (14.3\%). Meanwhile, (60\%) of patients in age group 4 (56-60 years) were female compared to males $(40 \%)$. Endogenous Estrogen is believed to protect younger females through its effect on fat distribution, blood lipids and coagulation. [15] While the increased prevalence of CHD in older females may be attributed to inadequacy in risk factor control (like hypertension, diabetes mellitus and obesity).

Education status was higher in males, with only $(4.1 \%)$ and $(14.9 \%)$ reporting no education and having completed primary school, respectively, compared to (34.6\%) and $(19.2 \%)$ in females $(p$-value $<0.001)$. That was in agree with the results of CardioRisk project which showed that among 1681 Egyptian patients presented with ACS, males were only $(7 \%)$ and $(17 \%)$ reporting no education and having completed primary school only, respectively, compared to $(26 \%)$ and $(25 \%)$ of females. [16]

The most common presentation of premature CHD in our study population was STEMI (53\%) and this diagnosis was more prevalent in males compared to females [(60.8\%) vs $(30.8 \%),(p<0.001)]$. Meanwhile, NSTEMI diagnosis was present in $(29 \%)$ of patients and was more prevalent in females compared to males [(53.8\%) vs $(20.3 \%),(p=0.008)]$. Earlier studies have stated that the most common presentation of premature CHD was STEMI and that it was more prevalent in males compared to females. [17, 18] Currently, there are multiple ongoing prospective studies to evaluate subclinical markers of atherosclerosis that may be responsible for this finding.

Diabetes mellitus (DM), hypertension (HTN), obesity, dyslipidemia, cigarette smoking and past family history of premature CHD, are well-known risk factors for early onset CHD development. [19-21] Our study showed the same pattern of high prevalence of these risk factors among the studied population. We also noticed that there was an 
incremental rise in prevalence of metabolic risk factors with age, as older age groups showed higher prevalence of DM, HTN and obesity. This was also evident in previous studies of premature CHD. [22-24]

Gender difference in the rates of risk factors was clearly evident, as males had higher rates of smoking, whereas females had higher rates of metabolic risk factors; DM, HTN, obesity and FH. (Figure 1)-(Figure 2) These findings were also evident in multiple previous studies. [20, 21, 25] The "Role of Gender on Outcomes of Young Acute MI Patients" (VIRGO) study which enrolled 3,501 AMI patients aged 1855 years to assess sex difference in risk factors also showed higher prevalence of metabolic risk factors among females compared to males. [18]

Smoking is important and modifiable risk factor known for premature CHD. Several previous studies have shown smoking as the most important risk factor among patients with premature CHD. [20, 21] Our study showed that smoking was the dominant risk factor (64\%). Aggarwal et al. reported even higher prevalence of cigarette smoking $(74.3 \%)$ in patients with premature CHD. [26] The INTERHEART study stated that the ACS risk attributable to smoking is markedly higher in younger age groups and that young male current smokers have the highest risk for coronary artery disease. [27]

Egypt is one of the 21 countries and territories of Middle East and North Africa (MENA) Region representing 29 diabetes organizations. Egypt currently has one of the highest prevalence of obesity in the MENA region, only after Saudi Arabia and the United Arab Emirates. [28] Obesity has been extensively studied as a risk factor for premature CHD. Marcial et al. stated that obesity was present in $(45.9 \%)$ in patients with premature CHD and the study concluded that obesity was the most important treatable predictor of premature CHD in young adult population. [29] Our study showed increased prevalence of obesity (64\%) and even higher prevalence of abdominal obesity $(71 \%)$.

According to Framingham study, diabetic patients have a 2 to 4 fold increased risk for developing of premature CHD and death. [30] We found that prevalence of diabetes mellitus was (34\%). This prevalence of DM in our patients with premature CHD was more than twice the prevalence seen in in the general Egyptian population. According to the last update of International Diabetes Federation (IDF) MENA published in 25-2-2020, prevalence of DM in adult population in Egypt was $(15.2 \%)$. [31]

Positive family history is an important risk factor and a finding that suggests the importance of genetic predisposition of CHD. Compared to older populations, those with early onset CHD seemed to have double the prevalence of family history of CHD. [32] The prevalence of a positive family history in patients presented with premature CHD was up to $(75 \%)$ in some studies [32]; however, it was (43\%) in our study.

Another premature CHD risk factor studied was dyslipidemia, which increased the risk of premature CHD by twofold. [33, 34] A correlation has been found between the blood concentration of lipids and the risk of cardiovascular disease. Studies have shown that a reduction in the TC and LDL-C levels of $(1 \%)$ is associated with a reduction in the risk of coronary heart disease by (2\%). [35] Hypercholesterolemia was present in $(62 \%)$ of patients, Low HDL-C in (65\%), increased LDL-C in $(67 \%)$ and increased TG in (47\%) of patients.

The prevalence of definite/probable $\mathrm{FH}$ among patients with early CHD is not clear as it is widely variable among different studies. According to Dorsch et al., their Study included 292 patients younger than 60 years old with ACS and the prevalence of definite/probable FH was (12.3\%). [36] While in EUROASPIRE IV survey which enrolled 7,044 patients across 24 European countries who had been admitted for a coronary event, the prevalence of definite/probable FH was widely variable among different countries; prevalence of definite/ probable hypercholesterolemia in Bosnia reached $(20.8 \%)$ while in Finland was estimated (3.4\%). [25] In our study, prevalence of definite/probable $\mathrm{FH}$ was estimated as $(26 \%)$. This wide variation in the prevalence of FH may be due to variable criteria defining cut-off age of premature CHD in males and females, difference of inclusion criteria between studies, different ethnicities and differences in the diagnostic criteria used. This might also be explained by differences between the centers participating in different studies, as tertiary centers recruiting more severely affected patients have much higher chance of diagnosing FH.

\section{Conclusion}

Among patients with premature CHD, the prevalence rate of different risk factors, such as smoking, obesity, hyperlipidemia, central obesity, HTN, DM and family history of premature CHD were high. Smoking, obesity and dyslipidemia seem up until now the most likely causes of premature onset CHD. Familial hypercholesterolemia is frequent among patients with premature CHD. This may advocate for better screening of FH during the hospital stay, in order to plan specific referral to lipid clinics for diet counselling, extended maintenance of high dose statin therapy, and identification of family members. Gender difference in the rates of risk factors was clearly evident, as males had higher rates of smoking, whereas females had higher rates of metabolic risk factors; DM, HTN, obesity and FH. Our data can be used to plan different preventative strategies in selected younger populations to help decrease the burden of premature CHD and close the current gap in coronary heart disease prevention.

\section{Availability of Data and Materials}

The datasets used and/or analysed during the current study are available from the corresponding author on reasonable request.

\section{Conflicting Interest}

The authors declare that they have no competing interests. 


\section{References}

[1] K. Okrainec, D. K. Banerjee, and M. J. Eisenberg, "Coronary artery disease in the developing world," Am. Heart J., vol. 148, no. 1, pp. 7-15, 2004, doi: 10.1016/j.ahj.2003.11.027.

[2] D. N. Vikulova et al., "Premature Atherosclerotic Cardiovascular Disease: Trends in Incidence, Risk Factors, and Sex-Related Differences, 2000 to 2016.," J. Am. Heart Assoc., vol. 8, no. 14, p. e012178, Jul. 2019, doi: 10.1161/JAHA.119.012178.

[3] V. J. Leijdekkers, A. C. Vahl, J. J. M. Leenders, P. C. Huijgens, R. O. B. Gans, and J. A. Rauwerda, "Risk factors for premature atherosclerosis," Eur. J. Vasc. Endovasc. Surg., vol. 17, no. 5, pp. 394-397, 1999, doi: 10.1053/ejvs.1998.0775.

[4] "Prevalence of uncontrolled risk factors for cardiovascular disease: United States, 1999-2010-PubMed." https://pubmed.ncbi.nlm.nih.gov/23101933/ (accessed Jul. 23, 2020).

[5] K. Nasir et al., "Family history of premature coronary heart disease and coronary artery calcification: Multi-Ethnic Study of Atherosclerosis (MESA)," Circulation, vol. 116, no. 6, pp. 619-626, Aug. 2007, doi: 10.1161/CIRCULATIONAHA.107.688739.

[6] M. A. Austin, C. M. Hutter, R. L. Zimmern, and S. E. Humphries, "Genetic Causes of Monogenic Heterozygous Familial Hypercholesterolemia: A HuGE Prevalence Review," Am. J. Epidemiol., vol. 160, no. 5, pp. 407-420, Sep. 2004, doi: $10.1093 / \mathrm{aje} / \mathrm{kwh} 236$.

[7] P. A. James et al., "2014 evidence-based guideline for the management of high blood pressure in adults: report from the panel members appointed to the Eighth Joint National Committee (JNC 8).," JAMA, vol. 311, no. 5, pp. 507-520, Feb. 2014, doi: 10.1001/jama.2013.284427.

[8] A. D. Association, "Diagnosis and classification of diabetes mellitus," Diabetes Care, vol. 33, no. SUPPL. 1. American Diabetes Association, p. S62, Jan. 2010, doi: 10.2337/dc10-S062.

[9] H. B. Brewer, "New features of the national cholesterol education program adult treatment panel III lipid-lowering guidelines," Clin. Cardiol., vol. 26, no. S3, pp. 19-24, Apr. 2003, doi: 10.1002/clc.4960261505.

[10] F. Q. Nuttall, "Body mass index: Obesity, BMI, and health: A critical review," Nutrition Today, vol. 50, no. 3. Lippincott Williams and Wilkins, pp. 117-128, May 17, 2015, doi: 10.1097/NT.0000000000000092.

[11] S. Czernichow, A. P. Kengne, E. Stamatakis, M. Hamer, and G. D. Batty, "Body mass index, waist circumference and waist-hip ratio: Which is the better discriminator of cardiovascular disease mortality risk? Evidence from an individual-participant meta-analysis of 82864 participants from nine cohort studies," Obes. Rev., vol. 12, no. 9, pp. 680687, Sep. 2011, doi: 10.1111/j.1467-789X.2011.00879.x.

[12] F. Civeira et al., "Guidelines for the diagnosis and management of heterozygous familial hypercholesterolemia," Atherosclerosis, vol. 173, no. 1, pp. 55-68, 2004, doi: 10.1016/j.atherosclerosis.2003.11.010.

[13] R. C. Team, "R: A language and environment for statistical computing," 2013.

[14] G. Egiziano, S. Akhtari, L. Pilote, and S. S. Daskalopoulou, "Sex differences in young patients with acute myocardial infarction," Diabet. Med., vol. 30, no. 3, Mar. 2013, doi: 10.1111/dme.12084.

[15] K. A. Matthews et al., "Are Changes in Cardiovascular Disease Risk Factors in Midlife Women Due to Chronological Aging or to the Menopausal Transition?," J. Am. Coll. Cardiol., vol. 54, no. 25, pp. 2366-2373, 2009, doi: 10.1016/j.jacc.2009.10.009.

[16] A. Reda et al., "The pattern of risk-factor profile in Egyptian patients with acute coronary syndrome: Phase II of the Egyptian cross-sectional CardioRisk project," Cardiovasc. J. Afr., vol. 30, no. 2, pp. 87-94, 2019, doi: 10.5830/CVJA2018-074.

[17] M. A. Siddique et al., "Age-Related Differences of Risk Profile and Angiographic Findings in Patients with Coronary Heart Disease," Bangabandhu Sheikh Mujib Med. Univ. J., vol. 3, no. 1, pp. 13-17, Jul. 2010, doi: 10.3329/bsmmuj.v3i1.5508.

[18] E. C. Leifheit-Limson et al., "Sex differences in cardiac risk factors, perceived risk, and health care provider discussion of risk and risk modification among young patients with acute myocardial infarction the VIRGO study," $\mathrm{J}$. Am. Coll. Cardiol., vol. 66, no. 18, pp. 1949-1957, Nov. 2015, doi: 10.1016/j.jacc.2015.08.859.

[19] A. Gupta et al., "Trends in acute myocardial infarction in young patients and differences by sex and race, 2001 to 2010," J. Am. Coll. Cardiol., vol. 64, no. 4, pp. 337-345, Jul. 2014, doi: 10.1016/j.jacc.2014.04.054.

[20] E. C. Leifheit-Limson et al., "Prevalence of traditional cardiac risk factors and secondary prevention among patients hospitalized for acute myocardial infarction (AMI): Variation by age, sex, and race," J. Women's Heal., vol. 22, no. 8, pp. 659-666, Aug. 2013, doi: 10.1089/jwh.2012.3962.

[21] J. G. Canto et al., "Number of coronary heart disease risk factors and mortality in patients with first myocardial infarction," JAMA-J. Am. Med. Assoc., vol. 306, no. 19, pp. 2120-2127, Nov. 2011, doi: 10.1001/jama.2011.1654.

[22] M. Afifi, "Antecedant risk factors and their control in young patients with a first myocardial infarction.," Singapore Med. J., vol. 47, no. 6, pp. 554-5; author reply 555-6, Jun. 2006, Accessed: Jul. 28, 2020. [Online]. Available: http://www.ncbi.nlm.nih.gov/pubmed/16752030.

[23] D. D. McManus et al., "Thirty-year (1975 to 2005) trends in the incidence rates, clinical features, treatment practices, and short-term outcomes of patients $<55$ years of age hospitalized with an initial acute myocardial infarction," Am. J. Cardiol., vol. 108, no. 4, pp. 477-482, Aug. 2011, doi: 10.1016/j.amjcard.2011.03.074.

[24] F. H. Zimmerman, A. Cameron, L. D. Fisher, and N. Grace, "Myocardial infarction in young adults: Angiographic characterization, risk factors and prognosis (coronary artery surgery study registry)," J. Am. Coll. Cardiol., vol. 26, no. 3, pp. 654-661, 1995, doi: 10.1016/0735-1097(95)00254-2.

[25] G. De Backer et al., "Prevalence and management of familial hypercholesterolaemia in coronary patients: An analysis of EUROASPIRE IV, a study of the European Society of Cardiology.," Atherosclerosis, vol. 241, no. 1, pp. 169-175, Jul. 2015, doi: 10.1016/j.atherosclerosis.2015.04.809. 
[26] A. Aggarwal, S. Aggarwal, A. Goel, V. Sharma, and S. Dwivedi, "A retrospective case-control study of modifiable risk factors and cutaneous markers in Indian patients with young coronary artery disease," JRSM Cardiovasc. Dis., vol. 1, no. 3, pp. 1-8, Jun. 2012, doi: 10.1258/cvd.2012.012010.

[27] K. K. Teo et al., "Tobacco use and risk of myocardial infarction in 52 countries in the INTERHEART study: a casecontrol study," Lancet, vol. 368, no. 9536, pp. 647-658, Aug. 2006, doi: 10.1016/S0140-6736(06)69249-0.

[28] S. Mendis, S. Davis, and B. Norrving, "Organizational update: the world health organization global status report on noncommunicable diseases 2014; one more landmark step in the combat against stroke and vascular disease.," Stroke, vol. 46, no. 5, pp. e121-2, May 2015, doi: 10.1161/STROKEAHA.115.008097.

[29] J. M. Marcial and P. I. Altieri, "Obesity and premature coronary artery disease with myocardial infarction in Puerto Rican young adults.," Bol. Asoc. Med. P. R., vol. 107, no. 3, pp. $70-74,2015$.

[30] S. R. Preis et al., "Trends in all-cause and cardiovascular disease mortality among women and men with and without diabetes mellitus in the Framingham Heart Study, 1950 to 2005.," Circulation, vol. 119, no. 13, pp. 1728-1735, Apr. 2009, doi: 10.1161/CIRCULATIONAHA.108.829176.

[31] "Members." https://idf.org/our-network/regionsmembers/middle-east-and-north-africa/members/34egypt.html (accessed Jul. 30, 2020).
[32] S. K. Hosseini et al., "Clinical features, management and inhospital outcome of ST elevation myocardial infarction (STEMI) in young adults under 40 years of age.," Monaldi Arch. chest Dis. =Arch. Monaldi per le Mal. del torace, vol. 72, no. 2, pp. 71-76, Jun. 2009, doi: 10.4081/monaldi.2009.331.

[33] K. O. Akosah, E. Gower, L. Groon, B. L. Rooney, and A. Schaper, "Mild hypercholesterolemia and premature heart disease: do the national criteria underestimate disease risk?," $J$ Am. Coll. Cardiol., vol. 35, no. 5, pp. 1178-1184, Apr. 2000, doi: 10.1016/s0735-1097(00)00556-8.

[34] S. K. Bansal, S. Agarwal, and M. K. Daga, "Conventional and Advanced Lipid Parameters in Premature Coronary Artery Disease Patients in India," J. Clin. DIAGNOSTIC Res., vol. 9, no. 11, p. BC07, 2015, Accessed: Jul. 30, 2020. [Online]. Available: www.jcdr.net.

[35] K. Mahdy Ali, A. Wonnerth, K. Huber, and J. Wojta, "Cardiovascular disease risk reduction by raising HDL cholesterol--current therapies and future opportunities.," $\mathrm{Br}$. J. Pharmacol., vol. 167, no. 6, pp. 1177-1194, Nov. 2012, doi: 10.1111/j.1476-5381.2012.02081.x.

[36] M. F. Dorsch, R. A. Lawrance, N. P. Durham, and A. S. Hall, "Familial hypercholesterolaemia is underdiagnosed after AMI," British Medical Journal, vol. 322, no. 7278. BMJ Publishing Group, p. 111, Jan. 13, 2001, doi: 10.1136/bmj.322.7278.111. 